\title{
Pump As Turbine With Induction Generators In Pico Hydro For Electrification of High Terrain Areas: A Review
}

\author{
Ajit Singh Aidhen ${ }^{{ }^{*}}$ and Pratibha H. Gaikwad ${ }^{\dagger}$ \\ †Marine Engineering Dept., Tolani Maritime Institute, Talegaon-Chakan Road, Pune. Maharashtra, India. \\ ^Electrical and Electronics Dept., Tolani Maritime Institute, Talegaon-Chakan Road, Pune. Maharashtra, India. \\ Accepted 01 Sept 2016, Available online 02 Sept 2016, Vol.6, No.5 (Oct 2016)
}

\begin{abstract}
About 85\% of the energy use in US and world is obtained through fossil fuels the prices of which are always growin. Around $16 \%$ of the electrical energy supply generated in world is through hydro power. In rural high terrain areas with low population density the energy per capita is low compared to city needs. Grid supply to these areas is not economical. RE presently is costlier compared to fossil-based and nuclear energy. Micro hydro and Pico- hydro are most appropriate for rural high terrain areas with water streams. The initial cost mainly involves construction and equipment cost. Pico-hydro plant does not require construction of dam it is a run-off-river plant. Pumps as turbine provide huge relief in the equipment cost. Centrifugal pump which are readily available have advantage over custom made turbines for micro and Pico hydro power generation. This review presents suitability, limitations, and selection criteria for PAT and review of research carried out by other researchers. Induction generators are useful in applications such as mini, micro and Pico hydro power plants because they can recover energy with relatively simple controls. The Selection of capacitors for induction generator used for standalone Pico hydro is also explained in this paper.
\end{abstract}

Keywords: The Pico Hydro, Pump As Turbine, Renewable Energy, Induction generator.

\section{Introduction}

India's 1.25 billion population of which about 300 million live without electricity. More than 75 million households (45\% of the total rural households) are yet to be electrified (Census of India, 2011). As per latest data, about 19,909 villages are yet to be electrified (Progress report of village electrification as on 31-012015 as per 2011). The Government has up-scaled the target of renewable energy capacity to $175 \mathrm{GW}$ by the year 2022 which includes $100 \mathrm{GW}$ from solar, $60 \mathrm{GW}$ from wind, $10 \mathrm{GW}$ from bio-power and $5 \mathrm{GW}$ from small hydro-power. The Ministry of Non-Conventional Energy Resources, Government of India recognized numerous sites in North India, generally in the Himalayan Range for the development of micro hydro power plants ranging from 15 to $50 \mathrm{~kW}$. The MNRE has renowned more than 6000 streams in north-east and north regions of India, that are not suitable for installation of large hydro power plants but are favorable for electricity generation in the range of 5100kW. Pico, Mini, micro and small hydro power schemes can be installed on such water streams (Rawal\& Kshirsagar, 2007)
Table 1.Classification of hydro power plants is as follows

\begin{tabular}{|c|c|}
\hline Type & Capacity \\
\hline $\begin{array}{c}\text { Large- } \\
\text { Hydro }\end{array}$ & $\begin{array}{r}\text { More than } 100 \mathrm{MW} \text { and usually feeding into a } \\
\text { large electricity grid }\end{array}$ \\
\hline $\begin{array}{c}\text { Medium - } \\
\text { Hydro }\end{array}$ & $15-100 \mathrm{MW}$ - usually feeding a grid \\
\hline $\begin{array}{c}\text { Small - } \\
\text { Hydro }\end{array}$ & $1-15 \mathrm{MW}$ - usually feeding into a grid \\
\hline $\begin{array}{c}\text { Mini - } \\
\text { Hydro }\end{array}$ & $\begin{array}{c}\text { Above } 100 \mathrm{~kW} \text {, but below } 1 \mathrm{MW} \text {; either } \\
\text { standalone schemes or more often feeding into } \\
\text { the grid. }\end{array}$ \\
\hline $\begin{array}{c}\text { Micro - } \\
\text { Hydro }\end{array}$ & $\begin{array}{c}\text { From } 5 \mathrm{~kW} \text { up to } 100 \mathrm{~kW} \text {; usually providing power } \\
\text { for a small community or rural industry in remote } \\
\text { areas away from grid }\end{array}$ \\
\hline $\begin{array}{c}\text { Pico - } \\
\text { Hydro }\end{array}$ & From a few hundred watts up to $5 \mathrm{~kW}$ \\
\hline
\end{tabular}

\subsection{Pico-Hydro}

Pico-hydro covers hydroelectric power generation under 5kW.In rural high terrain areas Pico hydro systems can be used as standalone systems where grid connection is not economical. Pico-hydropower is easy to operate and maintain. Wind power plants have associated noise pollution and biomass based energy systems cause environmental pollution. Pico hydro power plants are useful for small industries, 
agriculture and to power home appliances in remote high terrain rural areas. These plants are run of river type and have low initial cost as construction of dam is not required.

These areas cannot be provided with grid power as it would be uneconomical. Renewable energy based decentralized electricity generation is an appropriate solution. M.R. Nouni et al found that among renewable energy technologies, micro hydro is the cheapest to install, operate and maintain (Nouni, et al., 2009)

\section{Pump as Turbine (PAT)}

Hydropower systems generate electrical energy by converting the energy of falling water to mechanical energy with a turbine and from mechanical to electrical energy by generators coupled to turbines. In case of remote rural and high terrain areas it is more appropriate to use a pump coupled with induction motor as custom made turbines are expensive.
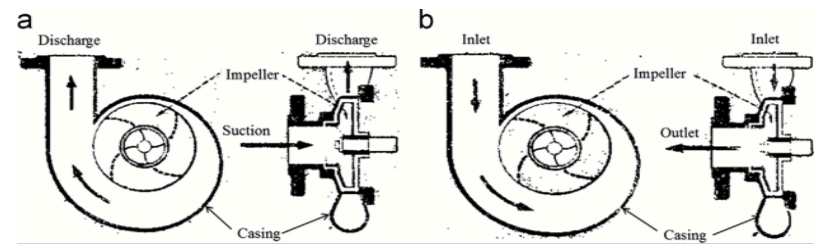

Fig 1. Centrifugal pump in (a) pump and (b) turbine modes

The pump is made to rotate in reverse by flowing water supplied to its discharge end through penstock and the induction motor is used as generator by adding capacitors as explained in detail in later section of this paper. The concept is as shown in Fig.2. (Vasanthakumar,2014)

\subsection{The main advantages of PAT are as follows}

Centrifugal pumps are readily available for a wide range of heads and flows in a large number of standard sizes, their spare parts are easily available, they are easy to install being a mono block unit requiring less space and use standard pipe fittings. Direct drive arrangement between pumps and motor have low friction which provides 5\% savings in output power. They are simpler constructions with fewer bearings with longer bearing life requiring less maintenance and are available at lower cost.

\subsection{Limitations to using mono-block pump motor unit as PAT}

The generator speed control requires turbine speed to be controlled which limits the range of flow rates for PAT performance to suit to the site conditions. Mechanical loads cannot be connected directly to PAT. (Jafar, 2000)

\subsection{Current applications of PAT}

PAT are currently in use for small pump storage power stations, irrigation systems, energy recovery as in water distribution systems, Reverse Osmosis systems, sewage systems and as pressure reducing valves.

\subsection{Limitations of Pico - hydro and PAT}

Pico-hydro requires suitable run of water site with suitable topography (Jafar, 2000). Pico - hydro requires transportation of equipment to remote rural high terrain areas. It requires technical expertise and funding for setup. manufactures provide the characteristic curves of their pumps for pump mode operation but they do not provide the same for reverse mode operation of the pump. This is the major limitation in using a pump as a turbine as it is difficult to predict pump behavior and performance .Pump operates in turbine mode with higher head and discharge at the same rotational speed. (Paish, 2002).

\subsection{Power output approximation}

A rule of thumb in estimating power is: Power (watts) $=5 \times$ height (meters) $x$ flow (liters $/ \mathrm{sec}$ )

Power output $(\mathrm{kW})=$ Generating efficiency $\times \mathrm{g} \times$ Head $(\mathrm{m}) \times$ Flow $\left(\mathrm{m}^{3} / \mathrm{s}\right)$

Electricity production $(\mathrm{kWh})=$ Power output $(\mathrm{kW}) \times$ Annual operation time $(24 \mathrm{~h} \times 365$ days $) \times$ Capacity factor

Capacity factor $(\%)=$ Annual Electricity production $(\mathrm{kWh}) /$ [Rated power output $(\mathrm{kW}) \times$ Annual operation time]

\section{Pump Selection for PAT}

Centrifugal pumps available in market operates best at certain values of head and flow at these values it operates at its maximum efficiency known as best efficiency point (BEP). Specific head and volumetric flow at the site selected for installation of PAT is ascertained. These head and flow values are not same as BEP values for the pump. Pump in turbine mode would require higher values to overcome loss of energy. [13]. The pipe's diameter D, the Volumetric Flow $\mathrm{Q}$, the pipe length $\mathrm{L}$, and the coefficient of flow $\mathrm{C}$ used to calculate amount of energy lost in the pipe due to friction by Hazen-Williams equation:

$$
H_{L}=k L\left(\frac{\left(\frac{Q}{C}\right)^{1.852}}{D^{4.87}}\right)
$$

The sum of Pipe head loss and head loss in fittings due to friction gives the total head loss. The total head loss divided by total head which is the head loss ratio, if the ratio is greater than $20 \%$ a larger diameter pipe should 
be selected and if the ratio is less than $10 \%$, smaller diameter pipe should be selected. This Pipe Selection should be used to calculate effective head in meters (which is head available after consideration of head loss), Ideal Jet Velocity in $\mathrm{m} / \mathrm{s}$, Jet Power in watts, Best Efficiency Pump Flow in l/sec or in l/ min, Best Efficiency Head in meters and Estimated Power Output in kilo watts. Best efficiency flow and best efficiency head is calculated and centrifugal pump that matches these numbers is selected. Turbine efficiency and generator efficiency values can be obtained from manufacturer, in case of non-availability they can be estimated as 78\% turbine efficiency and $77 \%$ generator efficiency. End-suction centrifugal pump unit with 3 phase induction motors are readily available. The three-phase induction motor can be used as singlephase generator as mentioned in the later part of the paper. A pump with $1500 \mathrm{rpm}$ is preferable as it will have less bearing wear. Waterproof IP rating should be preferably 4 to 5 .

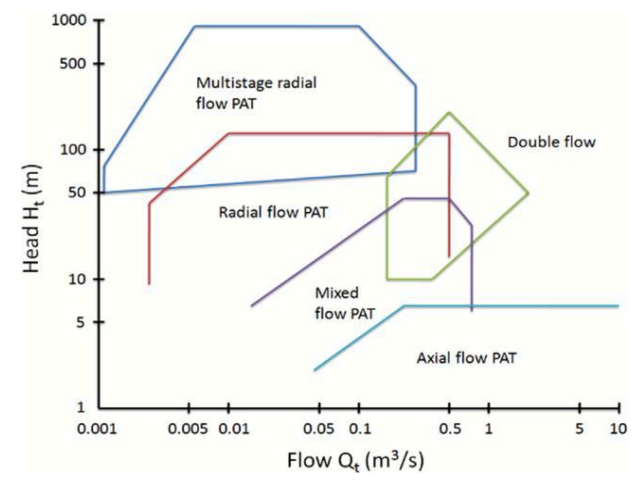

Fig 2. Pumps suitable as turbines based on head and flow

Table 2. US average level zed electricity cost 2015 based on US EIA statistics and analysis (Source: Annual Energy Outlook 2014)

\begin{tabular}{|c|c|}
\hline Power Plant Type & $\begin{array}{c}\text { Cost } \\
\mathbf{\$} \mathbf{k W} \text {-hr }\end{array}$ \\
\hline Coal & $\$ 0.10-0.14$ \\
\hline Natural Gas & $\$ 0.07-0.13$ \\
\hline Nuclear & $\$ 0.10$ \\
\hline Wind & $\$ 0.08-0.20$ \\
\hline Solar PV & $\$ 0.13$ \\
\hline Solar Thermal & $\$ 0.24$ \\
\hline Geothermal & $\$ 0.05$ \\
\hline Biomass & $\$ 0.10$ \\
\hline Hydro & $\$ 0.08$ \\
\hline
\end{tabular}

\section{Literature Review}

\subsection{Theoretical Investigation on PAT}

(Williams, 1994) investigated through experimental study on more than 30 different pumps; the study reveals that no particular method is suitable for generalized PAT performance prediction.
(Singh \& Nestmann, 2011) through an efficient model studied effect of rounding of impeller edge, this increases the overall efficiency at various head and discharge combinations.

(Derakhshan \& Nourbakhsh, 2008) provided for best efficiency point 'area ratio' method. Estimations are made by geometric parameter and through performance curves for every part of the pump.

\subsection{Numerical investigation on PAT}

(Rodrigues et al, 2003) This numerical study using CFD, where the pump is divided into various study zones such as pump casing, inlet and outlet, runner diameter and draft tube provides results that have a $10 \%$ error compared to results obtained experimentally at different load conditions.

(Natanasabapathi and Kshirsagar, 2004) investigated that structured gridding across the interface between stationary and revolving structure minimizes errors in the results obtained through CFD.

(Rawal \& Kshirsagar, 2007) studied losses in casing draft tube, runner in axial flow pump running in reverse mode through numerical analysis. Numerical analysis results at best efficiency points are comparable.

(Derakhshan \& Nourbakhsh, 2008) Simulation results with CFD on centrifugal pump with specific speed 23.5in direct and reverse modes compared with experimental results on same pump were not close. The study suggests requirement of better approach at turbine boundary.

(Barrio, et al, 2010) Study presents numerical analysis using CFD tool which explains flow considering impeller geometry at normal conditions and re-circulating fluid regions at high and low flow rates.

(Fecarotta, et al, 2011) studied pump as turbine performance under different flow conditions using CFD revealing computation mesh to perform faster and more appropriate simulations.

(Agarwal,2012) studied that the variation in CFD results can be reduced using finer mesh, numerical methods and turbulence models.

\subsection{Experimental investigation on PAT}

(Chapallaz, et al., 1992) investigated conversion factors obtained from the graphs for PAT were within satisfactory limits for BEP and also points away from BEP.

Fernandez et al [25] Experimental study on centrifugal pump in PAT mode at different speeds shows pumps turbine behavior can be estimated to certain extent and PAT curves can be obtained experimentally.

Joshi et al [26] Experimental investigation of PAT performance in a micro hydro producing $25 \mathrm{~kW}$ electric power provides for pump selection a correlation between turbine and pump specific speeds. 
Derakhshan and Nourbakhsh [27] Experimental study on four centrifugal pumps and correlations obtained from it are used to calculate BEP of PAT. The study suggests that for higher operating efficiency, lower ratios of discharge and head are preferable for pumps with high specific speed needs.

(Nautiyal, et al, 2011) Experimental outcome are used to suggest new correlations using BEP and specific speed in pump mode to attain turbine mode characteristics. Results obtained from correlations show very less deviation from ones obtained through experiment.

(Agarwal, 2012) Experiments performed on centrifugal pumps with specific speed range from 10 to 300 in turbine mode, the study provides a monogram which provides helps in selection of a pump for a particular site to be used in reverse mode.

(Raman, et al., 2013). Carried out experimental investigation on end suction centrifugal pump (CALGON) type of 15.36 specific speed .The BEP in turbine mode was found to be lower than BEP in pump mode.

\section{Induction Motor as Generator in Pico-hydro}

Induction motors with prime movers are used in hydro power plant for generation of electricity. In normal motor operation, the stator flux rotation is faster than the rotor rotation. This causes the stator flux to induce rotor currents, which create a rotor flux with magnetic polarity opposite to stator. In this way, the rotor is dragged along behind stator flux, with the currents in the rotor induced at the slip frequency. In generator operation, a prime mover (turbine or engine) drives the rotor above the synchronous speed (negative slip). The stator flux still induces currents in the rotor, but since the opposing rotor flux is now cutting the stator coils, an active current is produced in stator coils and the motor now operates as a generator, sending power back to the electrical grid. An induction machine requires externally supplied armature current; it cannot start on its own as a generator. A source of excitation current for magnetizing flux (reactive power) for the stator is still required, to induce rotor current. This can be supplied from the electrical grid or, once it starts producing power, from the generator itself. Active power delivered to the line is proportional to slip above the synchronous speed.

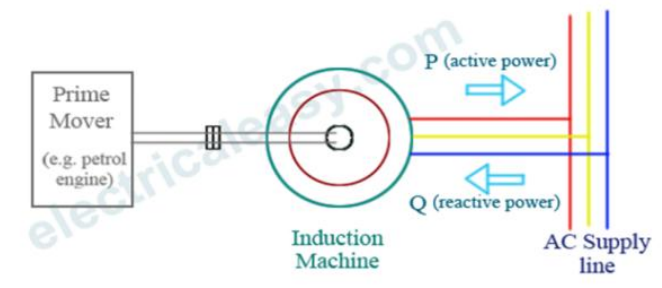

Fig 3. Induction Motor or Generator taking Reactive Power from Grid (Source: electricaleasy.com)

\subsection{Principle of operation of $I G$}

An induction generator or asynchronous generator is a type of alternating current (AC) electrical generator that uses the principles of induction motors to produce power. Induction generators operate by mechanically turning their rotors faster than synchronous speed. An induction generator produces electrical power when its rotor is turned faster than the synchronous speed.

An induction generator usually draws its excitation power from an electrical grid or self-excited by using phase-correcting capacitors. A capacitor bank must be used to supply reactive power to the motor when used in stand-alone mode. The reactive power supplied should be equal or greater than the reactive power that the machine normally draws when operating as a motor. Terminal voltage will increase with capacitance, but is limited by iron saturation.

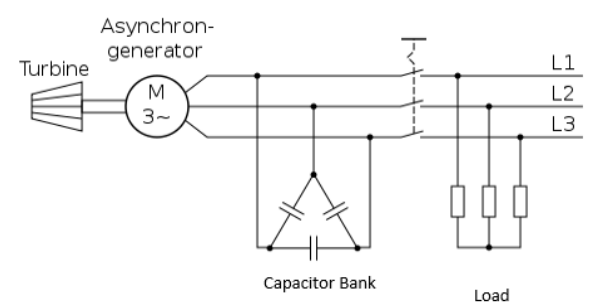

Fig 4. Capacitor bank connected to IG

\subsection{Difference between synchronous generator and induction generator}

1. In a synchronous generator, the waveform of generated voltage is synchronized with (directly corresponds to) the rotor speed. The frequency of output can be given as $\mathrm{f}=\mathrm{N} * \mathrm{P} / 120 \mathrm{~Hz}$. where $\mathrm{N}$ is speed of the rotor in rpm and $\mathrm{P}$ is number of poles. In case of inductions generators, the output voltage frequency is regulated by the power system to which the induction generator is connected. If induction generator is supplying a standalone load, the output frequency will be slightly lower (by 2 or $3 \%$ ) that is calculated from the formula $\mathrm{f}=\mathrm{N} * \mathrm{P} / 120$.

2. Separate DC excitation system is required in an alternator (synchronous generator) Induction generator takes reactive power from the power system for field excitation. If an induction generator is meant to supply a standalone load, a capacitor bank needs to be connected to supply reactive power.

3. Construction of induction generator is less complicated as it does not require brushes and slip ring arrangement. Brushes are required in synchronous generator to supply DC voltage to the rotor for excitation.

\subsection{Calculation of Capacitance for $I G$}

The torque produced by three phase induction motor depends upon, magnitude of rotor current, flux which interact with the rotor of three phase induction motor 
and is responsible for producing emf in the rotor part of induction motor, and the power factor of rotor of the three phase induction motor. Combining all these factors together we get the equation of torque as-

\section{$T \propto \phi I_{2} \cos \theta_{2}$}

Where, $\mathrm{T}$ is the torque produced by induction motor, $\Phi$ is flux responsible of producing induced $\mathrm{emf}, \mathrm{I}_{2}$ is rotor current,

$\cos \theta_{2}$ is the power factor of rotor circuit.

The flux $\Phi$ produced by the stator is proportional to stator emf $\mathrm{E}_{1}$.

i.e. $\Phi \propto \mathrm{E}_{1}$

For Pico-hydro power plants, small capacity induction generators can be used for the range of $1 \mathrm{HP}$ to $5 \mathrm{HP}$ capacity. Sample calculations are shown for 3 HP IG with following specifications -

Ratings of IG $-3 \mathrm{HP}=2.2371 \mathrm{KW}$

Poles - 4, 6, 8

Voltage $=240 \mathrm{~V}$

Full-load power factor is 0.8

Calculation of Full load current,

$\mathrm{KW}=\sqrt{3} \mathrm{E} \mathrm{I} \cos \theta$

$2.2371=\sqrt{3} \times 240 \times I \times 0.8$

$\mathrm{I}=6.727 \mathrm{~A}$

$\mathrm{I}=6 \mathrm{~A}$

Required capacitance per phase if capacitors are connected in delta:

Apparent power $\mathrm{S}=\sqrt{3} \mathrm{E} \mathrm{I}=1.73 \times 240 \times 6=2494.153$ VA

Active power $\mathrm{P}=\mathrm{S} \cos \theta=2494.153 \times 0.8=1995.32 \mathrm{~W}$

Reactive power $\mathrm{Q}=\sqrt{S^{2}-P^{2}}=1496.495 \mathrm{VAR}$

For a machine to run as an asynchronous generator, capacitor bank must supply minimum 1496.495 / 3 phases $=498.83$ VAR per phase.

Voltage per capacitor is $240 \mathrm{~V}$ because capacitors are connected in delta.

Capacitive current Ic $=$ Q $/ E=498.83 / 240=2.078 \mathrm{~A}$

Capacitive reactance per phase Xc $=\mathrm{E} / \mathrm{Ic}=115.49 \Omega$

Minimum capacitance per phase:

$\mathrm{C}=1 /(2 * \pi * \mathrm{f} \times \mathrm{Xc})=1 /(2 * 3.141 * 50 * 115.49)$

$=2.756 \times 10^{-5}$ farads

$=0.2756$ microfarad

It means capacitors connected in delta with value 0.2756 microfarad should be used in per phase of IG, which will provide required reactive power. If the load also absorbs reactive power, capacitor bank must be increased in size to compensate.
Table 3. Different capacity IG with appropriate capacitor values per phase

\begin{tabular}{|c|c|c|c|c|c|}
\hline $\begin{array}{c}\text { Mot } \\
\text { or } \\
\text { HP }\end{array}$ & $\begin{array}{c}\text { Motor } \\
\text { KW } \\
\text { rating }\end{array}$ & $\begin{array}{c}\text { Voltage } \\
(\mathrm{V})\end{array}$ & $\begin{array}{c}\text { Full load } \\
\text { Current } \\
\text { (A) }\end{array}$ & $\begin{array}{c}\text { VAR } \\
\text { /phase by } \\
\text { capacitor }\end{array}$ & $\begin{array}{c}\text { Capacitance } \\
\text { per phase } \\
\text { (microfarad) }\end{array}$ \\
\hline 1 & 0.745 & 240 & 2.24 & 186.23 & 0.1029 \\
\hline 2 & 1.491 & 240 & 4.48 & 372.29 & 0.2057 \\
\hline 3 & 2.237 & 240 & 6.727 & 498.83 & 0.2027 \\
\hline 4 & 2.982 & 240 & 8.969 & 745.7 & 0.412 \\
\hline 5 & 3.728 & 240 & 11.21 & 932.065 & 0.515 \\
\hline
\end{tabular}

\section{Example from a typical village in India}

In a typical village of about 200 households in North India, the following loads and consumption pattern is expected/assumed.

Lighting load: $48 \mathrm{~kW}$ for 365 days @6 hours per day (assumption: 4 light points of $60 \mathrm{~W}$ each per household)

Fan load: 90 kW for 120 days @3 hours per day

TV load: $37.5 \mathrm{~kW}$ for 365 days @ 3 hours per day

Total $=175.5 \mathrm{Kw} / 200$ families $=0.8775 \mathrm{~kW} /$ family

This can be fulfilled by Pico-hydro power plant.

\section{Conclusion}

1) In rural high terrain areas especially among the developing countries which suffer from energy problems supply of electricity through grid is not economically feasible. Growth of these areas cannot be ignored for holistic growth of a country. Pico hydro seems to be most appropriate alternative. Among renewable energy technologies. Pico hydro is the cheapest to install as standalone power generation system for these areas where water streams are available.

2) Power generated can be used for lighting, communication and small scale agricultural activities.RE technology can only be meaningful for such areas if they are low cost, simple and easy to maintain and operate. PAT offers a solution to these concerns.

3) The key advantage of using PAT in Pico - hydro systems is major savings in equipment cost as compared to using custom made turbines for a particular site.

4) There has been considerable work done by many researchers in PAT development. The review of these works suggests that CFD is an important tool in understanding of pumps behavior in turbine mode.

5) Approach for improving the efficiency of PAT should be focused on areas in pump which result in low cost implementation and that such modified components are readily available and their replacement is easier. 
6) The end suction radial discharge centrifugal pump is more readily available, cheaper easy to install and maintain. These pumps are available with different impeller material such as brass, bronze, cast iron, stainless steel, aluminum, plastic etc. The future work will be on selection of impeller material and impeller modification focusing on reducing internal losses and providing a cheaper and easy to replace concept.

\section{References}

US DOE (2014), Annual Energy Outlook.

Jain S. V. and Patel R. N., (2014), Investigations on pump running in turbine mode: A review of the state-of -the-art, Renewable and Sustainable Energy Reviews, vol. 30, pp. 841-868.

http://www.technologyreview.com/featuredstory/542091/i ndias-energy-crisis/

http://powerwatchindia.com/rural-electrificationchallenges-and-the-way-ahead/

http://www.indiainfoline.com/article/news-top-story/yearend-review-2015-ministry-of-new-and-renewable-energy115121600318_1.html

Rawal S. and Kshirsagar J.,(2007), Numerical simulation on a pump operating in a turbine mode, in Proceedings of the 23rd International Pump Users Symposium, pp. 21-27.

http://recap.apctt.org/Docs/MicroHydro.pdf

Anonymous, Micro Hydro Power - Pros and Cons,http://www.alternative-energy news.info/microhydro-power-pros-and cons / (January 2011)

Nouni M. R., Mullick S. C. and Kandpal T. C., (2009), Providing Electricity Access to Remote Areas in India: Niche Areas for Decentralized Electricity Supply, Renewable Energy 34, 430 - 434.

Vasanthakumar P., Arulmurugu A. , Vinothkumar R., Gowthamkumar R., Kumaresan S. , Prasath V., (2014), Investigation of Centrifugal Pump as Turbine : A Review Report , International Journal of Engineering Research \& Technology (IJERT) ,Vol. 3, pp.2287-2292.

Jafar $M_{,}(2000)$, Renewable Energy in the South Pacific Options and Constraints, Renewable Energy 19, 305 - 309

Paish 0.,(2002), Micro-hydro power: status and prospects, Proceedings of the Institution of Mechanical Engineers, Part A: Journal of Power and Energy, vol. 216, pp. 31-40.

A Guide to Pump-as-Turbine. Pico-Hydropower systems,By Chris Greacen and Megan Kerins.

http://www.nistep.go.jp/achiev/ftx/eng/stfc/stt036e/qr36p df/STTqr3606.pdf

Williams A.,(1994)The turbine performance of centrifugal pumps: a comparison of prediction methods, Proceedings of the Institution of Mechanical Engineers, Part A: Journal of Power and Energy, vol. 208, pp. 59-66.
Singh P. and Nestmann F., (2011) Internal hydraulic analysis of impeller rounding in centrifugal pumps as turbines, Experimental Thermal and Fluid Science, vol. 35, pp. 121134

Derakhshan S. and Nourbakhsh A. (2008)Theoretical, numerical and experimental investigation of centrifugal pumps in reverse operation,Experimental Thermal and Fluid Science, vol. 32,pp. 1620-1627.

Rodrigues A., Singh P., Williams A., Nestmann F., and Lai E., (2003) Hydraulic analysis of a pump as a turbine with CFD and experimental data, in IMechE seminar computational fluid dynamics for fluid machinery.

Natanasabapathi S. and Kshirsagar J.,(2004) Pump As Turbine-An Experience With CFX-5.6, Corporate research and engineering division. Pune, India, Kirloskar Bros. Ltd.

Rawal S. and Kshirsagar J.,(2007) Numerical simulation on a pump operating in a turbine mode, in Proceedings of the 23rd International Pump Users Symposium, pp. 21-27.

Barrio R., Fernández J., Parrondo J., and E. Blanco,(2010) Performance prediction of a centrifugal pump working in direct and reverse mode using Computational Fluid Dynamics, in International Conference on Renewable Energies and Power Quality, Granada, Spain.

Fecarotta O., Carravetta A., and Ramos H., (2011),CFD and comparisons for a pump as turbine: mesh reliability and performance concerns, Int J Energy Environ, vol. 2, pp. 3948.

Agarwal T.,(2012) Review of Pump as Turbine (PAT) for Micro-Hydropower, International Journal of Emerging Technology and Advanced engineering, vol. 2, pp. 163-168.

Chapallaz J., Eichenberger P., and Fischer G.,( 1992),Manual on Pumps Used as Turbines; MHPG Series; Vol. 11; Friedr, Vieweg \& SohnVerlagsgesellschaftmbH,

Fernandez J., Blanco E., Parrondo J., Stickland M., and Scanlon T.,(2004) Performance of a centrifugal pump running in inverse mode, Proceedings of the Institution of Mechanical Engineers, Part A:Journal of Power and Energy, vol. 218, pp 265-271.

Joshi S., Gordon A., Holloway L., and Chang L,(2005) Selecting a high specific speed pump for low head hydro-electric power generation. Canadian conference on Electrical and Computer Engineering,pp603-606

Nautiyal H., Varun V., Kumar A., and Yadav Sanjay,(2011),Experimental Investigation of Centrifugal Pump Working as Turbine for Small Hydropower Systems, Energy Science and Technology, vol. 1,pp. 79-86.

Raman N., Hussein I., Palanisamy K., and Foo B.,(2013) An experimental investigation of pump as turbine for micro hydro application, in IOP Conference Series: Earth and Environmental Science, p.012064.

Bhimara P.S. Electrical Machines

http://recap.apctt.org/Docs/MicroHydro.pdf 